\author{
Jurnal Aplikasi dan Inovasi Ipteks "SOLIDITAS” \\ Vol. 1 / No. 1 / April 2018 ; 9-14 \\ ISSN 2620-5076
}

\title{
PERANCANGAN MESIN CAMSHAFT UNTUK MEMPERBAIKI PROFIL CAMSHAFT YANG AUS
}

\author{
Eko Yohanes Setyawan ${ }^{1}$, Mochtar Asroni ${ }^{2}$, Totok Soegiarto ${ }^{3}$ \\ ${ }^{1,2,3}$ Jurusan Teknik Mesin, Fakultas Teknik Industri, Institut Teknologi Nasional Malang \\ yohanes@lecturer.itn.ac.id
}

\begin{abstract}
ABSTRAK
Masyarakat sekarang ini sudah banyak yang mencari kendaraan bermotor dengan emisi gas buang relatif rendah, konsumsi bbm semakin sedikit dan berbagai keunggulan lainnya. Sehingga kendaraan bermotor 4 langkah semakin banyak diminati karena mempunyai nilai ekonomis yang cukup tinggi jika dibandingkan dengan motor 2 langkah. salah satu permasalah yang banyak ditemukan yaitu camshaft pada motor 4 langkah karena pemakaian yang sudah lama maupun kesalahan dalam perawatan dapat merusak camshaft. Kegunaan camshaft yaitu untuk mengatur buka maupun tutup bahan bakar kedalam ruang bakar dengan bantuan klep. Sehingga dibutuhkan mesin camshaft untuk membentuk ulang profil camshaft yang sudah aus. Setelah dilakukan percobaan untuk mendisain profil camshaft yang baru dengan menggunakan mesin camshaft bersama mitra dihasilkan camshaft yang bagus sesuian keinginan dengan tingkat kepresisian yang tinggi.
\end{abstract}

Kata Kunci: camshaft, Aus, Bentuk Profil

\begin{abstract}
Today, many people are looking for motor vehicles with relatively low exhaust emissions, fewer fuel consumption and other advantages. So 4-stroke motor vehicle more desirable because it has a high economic value when compared with 2-step motor. one of the many problems found in the camshaft on a 4-stroke motor because old usage or errors in treatment can damage the camshaft. Usefulness of the camshaft is to set the open or close the fuel into the combustion chamber with the help of the valve. So it takes the camshaft engine to reshape the worn camshaft profile. After an experiment to design a new camshaft profile using a camshaft engine with a partner produced a good camshaft in accordance with the desire with a high level of precision.
\end{abstract}

Keywords: camshaft, aus, profile shape

\section{PENDAHULUAN}

Teknologi sekarang ini mengalami peningkatan dengan pesat, dimana jaman semakin maju kesadaran akan ramah lingkungan semakin meningkat. Masyarakat sekarang ini sudah banyak yang mencari kendaraan bermotor dengan emisi gas buang relatif rendah, konsumsi bbm semakin sedikit dan berbagai keunggulan lainnya. Sehingga kendaraan bermotor 4 langkah semakin banyak diminati karena mempunyai nilai ekonomis yang cukup tinggi jika dibandingkan dengan motor 2 langkah. Meskipun teknologinya sudah baik ternyata masih banyak yang kurang puas dengan performa motor bawaan pabrik sebagian dari masyarakat (Stevansa, 2014).

Dalam meningkatkan performa kendaraan bermotor dapat dilakukan salah satunya pergantian/ modifikasi disain camshaft sesuai kebutuhan (Swamulu, 2015). Camshaft adalah komponen penting pada motor 4 tak yang berfungsi mengatur sirkulasi bahan bakar dan udara yang masuk ke ruang bakar maupun mengatur gas hasil pembakaran keluar dari ruang bakar. Camshaft adalah salah satu komponen utama dalam motor bakar. Kinerjanya adalah untuk mengontrol buka dan tutup katup masuk dan buang bahan bakar. Karena tekanan yang besar sering menyebabkan keausan profil cam yang lebih lama dan mempengaruhi putaran gigi katup seperti kecepatan rotasi, perpindahan katup dan torsi. Di sisi lain, secara bersamaan yang paling serius, faktor kelelahan 
Setyawan, Perancangan Mesin Chamshaft Untuk Memperbaiki..

camshaft memulai pada konsentrasi tegangan dengan mudah terjadi. Oleh karena itu camshaft harus memiliki ketahanan aus yang sangat baik tetapi juga kekerasan yang yang memadai (R. V. Wanjari, 2013)

Berdasarkan penelitian yang sudah dilakukan perubahan LSA camshaft yang dipersempit menghasilkan daya maksimal yang semakin meningkat. Sedangkan perubahan LSA camshaft yang diperlebar menghasilkan daya maksimal yang semakin menurun. LSA camshaft yang dipersempit berdampak pada putaran mesin $4000 \mathrm{rpm}$ - $5500 \mathrm{rpm}$ daya yang dihasilkan menurun dibawah camshaft standar, sedangkan pada putaran mesin di atas 6000 rpm daya meningkat di atas camshaft standar. Perbedaan yang terjadi pada penelitian ini adalah pengaruh positif karena daya motor dapat meningkat pada putaran ( Siswanto, 2012). Dengan perubahan durasi camshaft dengan jalan menambah tinggi bukaan katup dapat meningkatkan tenaga mesin suzuki shogun fd 110 diantaranya torsi, daya efektif, daya mekanis, tekanan efektif, tekanan mekanis dan pemakaian bahan bakar dengan putaran mesin $10000 \mathrm{rpm}$ (Kristanto). Hasil numerik dibandingkan dengan data eksperimen dalam hal percepatan katup dan kecepatan sudut camshaft. Dengan menggunakan perbandingan ini, efektivitas model dinilai secara memuaskan. Camshaft yang disimulasikan menunjukkan bahwa model dapat menjadi alat yang sangat berguna untuk memprediksi dan memahami perilaku dinamis yang sebenarnya dari system dan untuk memperkirakan besarnya kekuatan dan dampak, sehingga dapat digunakan baik dalam optimasi desain dan diagnostic (Carlini, 2003).

Modifikasi atau memapas camshaft dengan tujuan menambah atau memperlebar camshaft dan meningkatkan efisiensi volumetrik dan merubah karakter sebuah mesin, agar mesin menghasilkan tenaga yang lebih besar dan sesuai kebutuhan (Gunawan, 2017). Berdasarkan pengujian performa, noken as rekondisi menghasilkan torsi dan daya yang hampir sama dengan noken as standar. Sedangkan pada noken as yang telah mengalami keausan dan noken as standar menghasilkan perbedaan torsi dan daya yang signifikan. Dari pengujian komposisi kimia, noken as merupakan material besi tuang. Noken as standar memiliki sifat fisis dan mekanis yang cukup baik. Sedangkan untuk noken as rekondisi memiliki sifat material yang getas (rentan retak). Noken as rekondisi pada aplikasinya dapat digunakan dengan baik dilihat dari hasil pengujian performanya. Akan tetapi dapat lebih baik lagi apabila dilakukan proses pengerasan (heat treatment) supaya sifat keuletan dari material dapat diperbaiki, sehingga dapat digunakan lebih tahan lama (Eri Diniardi, 2014). pengurangan emisi gas dan meningkatkan tenaga mesin (M. S. Al-Khaldi, 2016).

Baru-baru ini penelitian camshaft sengan durasi rendah menghasilkan unjuk kerja yang lebih besar pada putaran rendah namun buruk pada putaran tinggi, dan sebaliknya camshaft durasi tinggi menghasilkan unjuk kerja yang baik pada putaran tinggi namun buruk pada putaran rendah, Hasil eksperimen perbandingan unjuk kerja engine SINJAI $650 \mathrm{cc}$ SOHC port fuel injection menggunakan camshaft $260^{\circ}$, dengan peningkatan torsi $5.53 \%$, daya $5.53 \%$, bmep $5.53 \%$, efisiensi thermal $14.58 \%$, efisiensi volumetris $2.04 \%$ dan penurunan bsfc $17.905 \%$ dari camshaft standar pada putaran tinggi rentang 3000-5000 RPM (Darmawangsa, 2016).

Durasi dan tinggi angkatan katup dari after market camshaft memiliki angka yang lebih besar. Durasi katup hisap dari after market camshaft $256^{\circ}$, lebih besar dibandingkan standard camshaft yang memiliki nilai durasi $230^{\circ}$. Durasi katup buang dari after market camshaft $227^{\circ}$, lebih besar dibandingkan standard camshaft yang memiliki nilai durasi $209,5^{\circ}$. Lift atau tinggi angkatan katup hisap dan buang after market camshaft bernilai sama sebesar $6,95 \mathrm{~mm}$, lebih tinggi dari nilai tinggi angkatan katup dari standard camshaft sebesar $6,03 \mathrm{~mm}$. Nilai torsi dan daya yang dihasilkan standard camshaft lebih tinggi dibandingkan after market camshaft. Torsi maksimum yang dihasilkan standard camshaft sebesar 8,71 N.m pada putaran 4732 RPM, sedangkan torsi maksimum yang dihasilkan after market camshaft sebesar 6,79 N.m pada 6106 RPM. Daya maksimum yang dihasilkan standard camshaft sebesar 8,03 HP pada putaran 8103 RPM, sedangkan daya maksimum yang dihasilkan after market camshaft sebesar 7,1 HP pada 9223 RPM (Utomo, 2017).

Sehingga peneliti membaca peluang yang ada dalam usaha bengkel motor untuk mendisain dan membuat mesin bubut camshaft dengan diskusi dari beberapa bengkel yang ada di jawa timur 
dan jawa tengah, dengan adanya mesin ini sangat mendukung dalam pengerjaan camshaft. Mampu peresisi dalam proses pengerjaannya sesui dengan karakter motor yang diinginkan oleh mekanik, karena sesuai perhitungan yang sudah dilakukan. Dibandingkan menggunakan mesin gerinda hanya memainkan filing dari mekanik yang sering terjadi kesalahan dan harus mengulang dari pertama, karena menghasilkan karakter motor yang jelek, membuat motor tidak ada tenaga karena kesalahan dalam proses pengerjaannya ketidak sesuaian derajat maupun lift yang diinginkan membuat proses pengerjaan menjadi lama. Dengan adanya mesin bubut camshaft ini selain presisi juga dapat mempersingkat waktu. Sehingga mekanik diuntungkan selain dalam proses pengerjaannya bagus, mekanik dapat memperbaiki motor yang lainya sehingga penghasilan meningkat.

\section{METODE}

Merancang atau mendisain alat mesin camshaft dilakukan bersama mitra yang dijadikan tempat pengabdian masyarakat. Membuat mesin bubut camshaft dengan desain yang sudah disetujui sesuai masalahan yang dihadapi oleh mitra. Dengan menguji coba peralatan di tempat pengabdian masyarakat untuk mengetahui kemampuan mesin, bila ada kedala maupun ketidak sesuaian maupun kerusakan pada mesin bisa langsung diperbaiki dengan mitra secara bersamasama. Dari hasil diskusi dengan mitra sehingga didapatkan disain mesin camshaft yang diharapkan yaitu dengan cara duduk dibawah untuk mempermudah dalam pengerjaan camshaft

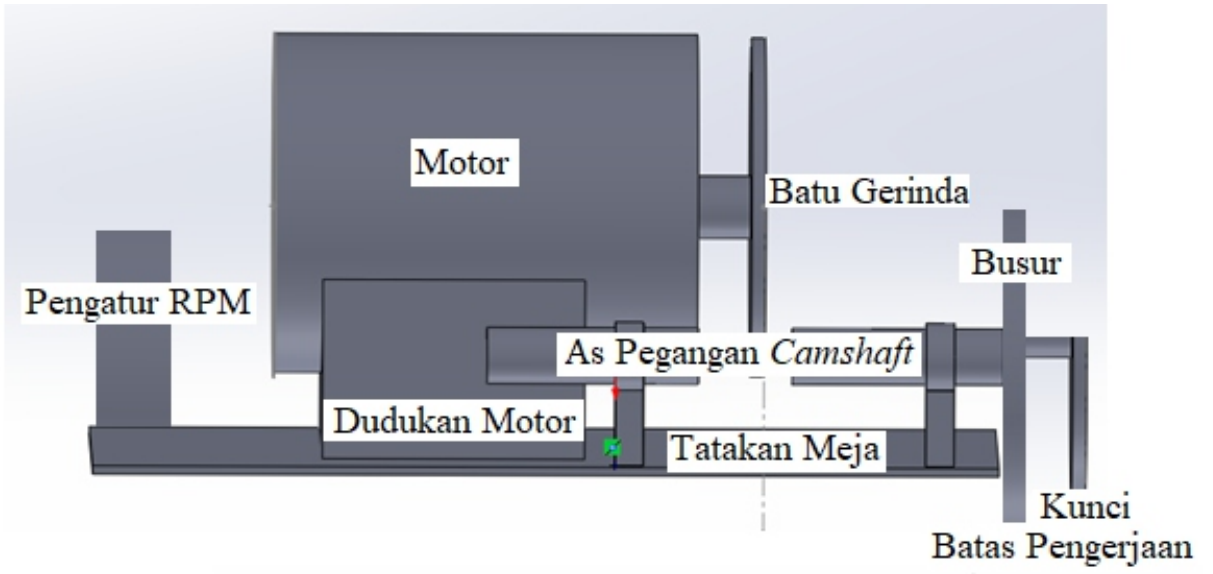

Gambar 1. Desain Mesin camshaft

Dari disain diatas maka digunakan beberapa alat penunjang dalam pengerjaaan mesin tersebut agar bisa digunakan. Sumber energi menggunakan motor listrik untuk menggerakan pulley yang ditransfer menggunakan belt yang sudah ditentukan terlebih dahulu dalam menggunakan sistem transmisi agar putaranya sesuai. Untuk mengikis camshaft digunakan kertas gosok kasar, setelah mendapatkan bentuk profil yang inginkan untuk finishing digunakan kertas gosok yang halus. Kemuadian siap dipasang kembali ke dalam mesin, untuk mengetahui kinerja dari camshaft salah satunya untuk mengetahui daya motor bisa digunakan perhitungan seperti dibawah ini.

Daya $(\mathrm{BHP})=2 \cdot \pi \cdot n \cdot T / 60.75$

\section{Dimana:}

BHP $=$ Brake house power (HP)

$\mathrm{T}=$ Torsi mesin (kgf.m)

$\mathrm{N} \quad=$ Putaran motor (rpm)

Sedangkan untuk mengetahui komsumsi bahan bakar setelah mengalami perubahan bentuk camshaft bisa digunakan persamaaan berikut ini.

$\mathrm{FC}=V_{f} \times 3600 / t \times 1000$

Dimana:

FC =Komsumsibahan bakar $(\mathrm{L} / \mathrm{h})$ 
Setyawan, Perancangan Mesin Chamshaft Untuk Memperbaiki..

$$
V_{f} \quad=\text { Volume komsumsi }(\mathrm{mL})
$$

$\mathrm{T}=$ Waktu komsumsi (s)

Konstruksi mesin sederhana dan proporsional memungkinkan setiap orang dapat mengoperasikannya dengan mudah sehingga memberikan efisiensi tenaga dan waktu serta memberikan kenyamanan terhadap mekanik. Seperti ditunjukan pada gambar 2. Konstruksi dudukan camshaft menggunakan besi pejal yang sudah di disan pada gambar 1 yang dipasangkan diatas dudukan camshaft sebagai tumpuan poros untuk memegang camshaft.

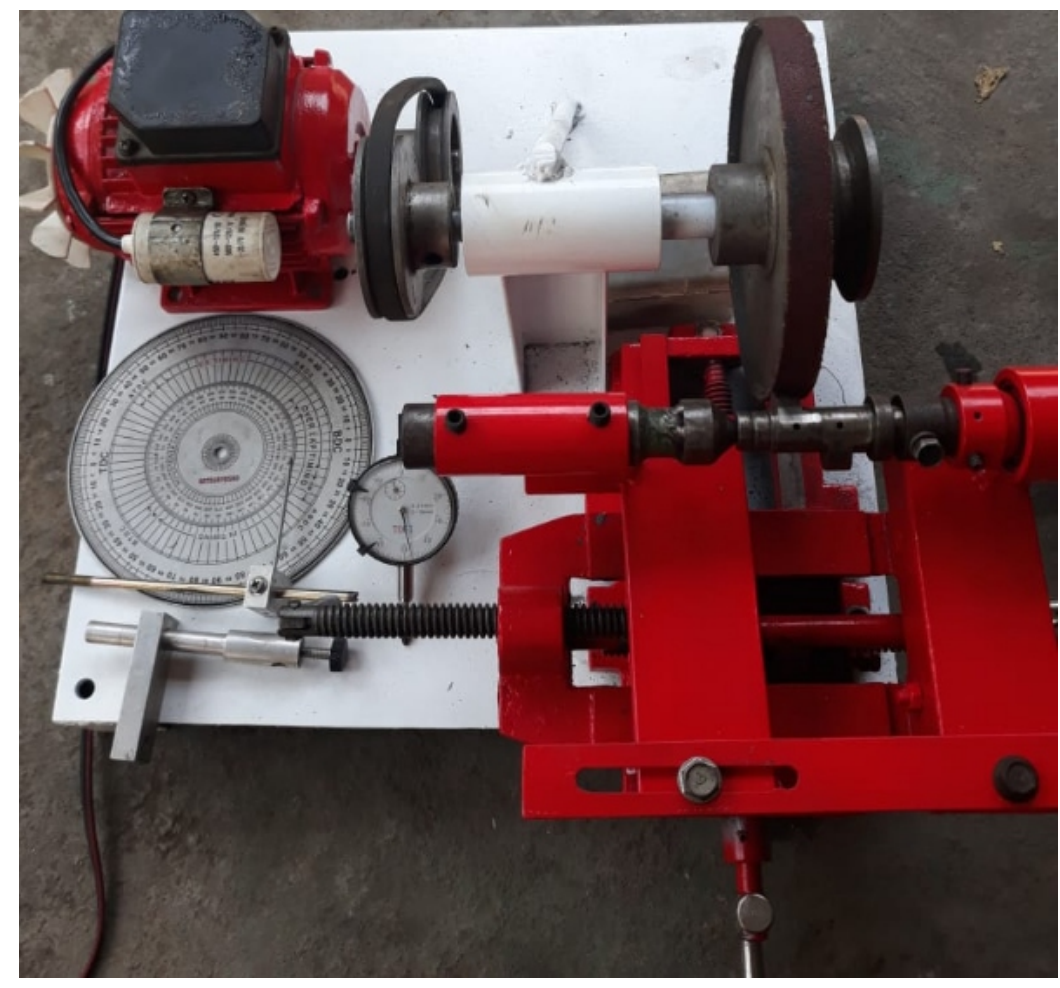

Gambar 2. Mesin camshaft

\section{HASIL DAN PEMBAHASAN}

Dalam Pelatihan dan pendampingan yang sudah dilakukan bersama mitra, yaitu tata cara pemakai mesin diharapkan dalam pelatihan tersebut mekanik atau pihak pengelola dapat menerapkan teknologi yang ada dan menganalisa kerusakan, sehingga pengelola dapat melakukan perawatan secara mandiri. Selain itu pelatihan juga dimaksudkan untuk mengenalkan cara kerja alat dan penggunaan alat camshaft.Mesin Camshaft merupakan salah satu jenis alat teknologi baru, mesin tersebut berfungsi sebagai alat untuk menata ulang bentuk camshaft sesui profil yang diinginkan. Cara kerja mesin tersebut sama dengan mesin gerinda yang telah ada sebelumnya, karena mesin tersebut kegunaannya sama untuk mengerinda atau mengikis camshaft menggunakaan mesin ini bisa dibatasi sudutnya dalam proses pengerjaan sedangkan memakai gerinda sudut diinginkan sangat sulit didapatkan. Diharapkan dengan menngunakan mesin ini dapat meningkatkan tingkat kepresisian maupun produksi pada bengkel mitra.

Dalam pertimbangan teknis, nilai teknis identik dengan kekuatan konstruksi mesin dimana pertimbangan teknis dari mesin camshaft konstruksi kuat dan proses pengerjaan. Karena mesin relatif mudah sehingga perawatan mesin dapat dilakukan dengan mudah dan murah. Pertimbangan nilai ekonomis memiliki keterkaitan antara kemampuan nilai teknis produk terhadap daya beli konsumen serta harga jual produk yang ditawarkan, diantaranya jaminan umur produk yang lama sebagai pendukung profit usaha calon pemakai. Suku cadang yang berkualitas dengan harga 
Jurnal Aplikasi dan Inovasi Ipteks, Vol. 1 / No. 1 / April 2018 ; 1-10

terjangkau dan mudah didapat serta perawatan yang mudah dikerjakan dan harga mesin yang terjangkau untuk kalangan bengkel menengah ke bawah.

Pertimbangan lingkungan sebagai pendukung diterimanya produk oleh masyarakat dan calon pembeli adalah mesin camshaft yang bebas polusi dan tidak bising, sebagai pendukung kenyamanan mekanik dalam pengerjaan. Keselamatan kerja merupakan syarat ketentuan mesin untuk dapat dikatakan layak pakai. Syarat tersebut dapat berupa bentuk komponen mesin yang berfungsi sebagai pengaman atau pelindung operator pada bagian mesin yang berpotensi menimbulkan kecelakaan kerja.

\section{DAMPAK DAN MANFAAT}

Salah satu permasalah yang banyak ditemukan pada camshaft motor 4 langkah karena pemakaiannya yang sudah lama maupun kesalahan dalam perawatan dapat merusak camshaft. Dengan adanya mesin camshaft dapat membentuk ulang profil camshaft yang sudah aus. Setelah dilakukan percobaan untuk mendesain profil camshaft yang baru dengan menggunakan mesin camshaft dihasilkan camshaft yang bagus sesuai karakter motor, bisa mengurangi pembelian camshaft, karena camshaft yang aus bisa diperbaiki kembali.

\section{KESIMPULAN}

Setelah dilakukan percobaan untuk mendesain profil camshaft yang baru dengan menggunakan mesin camshaft bersama mitra, dihasilkan camshaft yang bagus sesuai keinginan dengan tingkat kepresisian yang tinggi, untuk memutar pulley digunakan motor listrik. Sistem transmisi dan dudukannya yang terdiri dari poros, pulley, sabuk $v$-belt dan rangka dudukan bearing. Sedangkan untuk mengikis camshaft digunakan kertas gosok kasar, setelah mendapatkan bentuk profil yang inginkan untuk finishing digunakan kertas gosok yang halus. Konstruksi mesin sederhana dan proporsional memungkinkan setiap orang dapat mengoperasikannya dengan mudah sehingga memberikan efisiensi tenaga dan waktu serta memberikan kenyamanan untuk mekanik.

\section{UCAPAN TERIMA KASIH}

Ucapan terima kasih disampaikan kepada Lembaga Penelitian dan Pengabdian ITN Malang yang telah mensupport dalam bentuk dana untuk kelancaran program penelitian dan pengabdian yang telah dilakukan.

\section{DAFTAR PUSTAKA}

A.Carlini, A. R. (2003). A Non Linear Elastodynamic Model Of A Camshaft Supported By Journal Bearings.Aimeta '03, (Pp. 1-12).

Djiwo Soeparno Dan Eko Yohanes,2016. Mesin Teknologi Tepat Gunasabut Kelapa di UKM Sumber Rejeki Kabupaten Kediri. Seminar Nasional dan Gelar Produk 2016, Universitas Muhamadiyah Malang, Indonesia2016 576-582

Eri Diniardi, K. S. (2014). Analisis Sifat Mekanis Antara Noken As Standar Dan Noken As Rekondisi Pada Sepeda Motor. Sintek, 8(2), 16-21.

Firman Iffah Darmawangsa, B. S. (2016). Analisis Pengaruh Penambahan Durasi Camshaft Terhadap Unjuk Kerja Dan Emisi Gas Buang Pada Engine Sinjai 650 Cc. Jurnal Teknik Its, 2429.

Kristanto, D. (N.D.). Pengaruh Perubahan Durasi Camshaft Terhadap Performance Mesin Fd 110 Cc. Fakultas Teknik Universitas Islam Malang.

M. S. Al-Khaldi, M. K. (2016). Determination Of Optimum Valve Opening And Height In The 
Automotive Engine. Arpn Journal Of Engineering And Applied Sciences, 190-194.

R. V. Wanjari, T. C. (2013). Failure Of Camshaft. International Journal Of Innovative Technology And Exploring Engineering, 248-250.

Stevansa, P.A. (N.D.).

Stevansa, P. A. (2014). Pengaruh Penggunaan Camshaft Standard Dan Camshaft Racing Terhadap Unjuk Kerja Motor Bensin Empat Langkah.

Setyawan Eko Yohanes, Djiwo Soeparno and Sugiarto Totok. Simulation Model of Fluid Flow and Temperature Distribution in Porous Media Using Cylinder Convergent and Divergent Nozzle. Internasional Journal of Technology And Sciences. 201711

Utomo, O. T. (2017). Pengujian Standard Camshaft Dan After Market Camshaft Terhadap Unjuk Kerja Sepeda Motor 4 Langkah $110 \mathrm{Cc}$.

Vulleru Swamulu, N. N. (2015). Design And Analysis Of Cam Shaft For Multi Cylinder Engine. International Research Journal Of Engineering And Technology, 1144-1147.

Yoyok Drajat Siswanto, R. D. (2012). Pengaruh Variasi Lobe Separation Angle Camshaft Dan Variasi Putaran Mesin Terhadap Daya Pada Sepeda Motor Honda Supra X 125 Tahun 200. Nosel, 98-105.

Yuspian Gunawan, J. D. (2017). Perancangan Mesin Poles Serba Guna (Modifikasi Camshaft/Noken As). Enthalpy, 1-8. 